\title{
Moving to Beijing to Take Care of My Child with a Chronic Disease: How Does It Change My Own Identity?
}

\author{
Yiheng Yuan ${ }^{1, *}$
}

\author{
${ }^{1}$ Western Academy of Beijing \\ *Email: jimmyyuan2004@outlook.com
}

\begin{abstract}
Over the past decade, more Chinese people migrated to larger urban cities, such as Beijing, to seek better medical care for their seriously ill children. Often these people are desperate and burdened with medical expenses. In this process, the new role that they adapt to would, most likely, affect their identity. Hence, the objective of this study is to understand how to better support them and how they cope with the outside pressure. As a volunteer in the Children's Hope Foundation, the author can access these families and set up in-depth interviews with 6 respondents, all from different families. The author's past observations of these families would also be used as data. In conclusion, the "caregiver identity" influences migrants to Beijing for their children in their decision-making. This further results in emotional and mental stress yet have become a role they use to cope with their current problems.
\end{abstract}

Keywords: Caregiver, Gender, Identity Change, Identity Formation, Migration

\section{INTRODUCTION}

In 2020, a study was conducted "to analyse the changing trend and regularity of discharged patients from Hebei province in the central district of Beijing." Out of the data from 13 hospitals, which accumulated 441 million discharged patients from 2009-2018, 9.3\% were patients from Hebei province. According to the trend, the number of patients discharged in 2019 was approximately 71,455 , more than 21 times the number in 2009. With this present trend, it is evident that more and more patients across China are moving to the capital to seek medical care, and these people are becoming a prominent group. [7]

From statistics by the Chinese National Healthcare Security Administration, in January of 2021, approximately 296,000 person-times hospitalisation expenses were settled directly across provinces. Approximately 347,800 person-times paid outpatient fees directly across provinces were from the 12 pilot provinces, including Beijing-Tianjin-Hebei, Yangtze River Delta and 5 provinces (autonomous regions and municipalities) in Southwest China and other provinces (autonomous regions, municipalities), etc. These statistics outline the "across province direct payment method's" (translated from Chinese), a method to help those who need to pay for medical bills in a province, not of his/her residence, current situation. [12]

From the statistic above, a general picture can be drawn about the number of people who come to another province, especially Beijing, to seek medical care, among which a considerable group would be examined: families who move to Beijing to seek better care for their children with chronic diseases (in this study, chronic disease is defined as "Chronic diseases are defined broadly as conditions that last 1 year or more and require ongoing medical attention or limit activities of daily living or both" as defined by the CDC and translated by the author (About Chronic Diseases | CDC, n.d.)). This is a group with which I, as a helper at Children's Hope Foundation, have frequent contact. The children's hope foundation aims to help children across China and operates in multiple locations across China, including Beijing, Shanghai, Guangzhou etc. The organisation has helped over 20,000 handicapped orphans in receiving medical care and over 8000 families whose children came to Beijing to receive surgery. I am in a specific project the organisation managed named 助医小家项目 (“House for those who seek aid"), which is a project that provides cheap housing for families who come to seek medical attention for their children. [11] According to senior members in the organisation, on average, each of these 
"nursing homes" accepts 12 families per year, with 10 nursing homes scattered across Beijing and many more in Shanghai, Guangzhou etc. I have been in this project for over 2 years and met with these families around two or three times every month discounting foundationorganised additional fundraising activities or events. Throughout my time in this project, I often find many parents, though they may previously be farmers, migrant workers, white-collar workers etc. have been constrained to the house and, more specifically, to their child due to needing to care for their child's illness, a practice which results in immense medical bills. Though this is common practice amongst such families and has been often normalised, this new situation where the parents are jobless and need to care for their child seems to drastically alter the way these parents act and is considerably different from the role these individuals previously assumed, intrigues me. From a personal perspective, I would want to understand how people can adjust to new roles under immense pressure (in this case, their children on the brink of death); from a social perspective, it seems vital to find ways to better the support for this group of people, especially the relatively unexplored identity area of these people.

Though this group has not been specifically targeted by government policy, the Chinese government did demanded the "Promotion of network medical insurance and direct settlement of medical treatment in different places", (translated from Chinese) which means that these families who came to Beijing to receive medical treatment would have an easier time. Though some degree of policy is targeted at this group, challenges may remain. [13]

This then provokes the questions: what are the experiences of these families? And perhaps for better understanding, how does moving to Beijing change their identity, to which I would hypothesise that as these parents conform to caregiver roles, their identity would change in relation to their new role, gradually shifting from their old identity. With the aims of to, first, understand their daily challenges and how to support them more effectively from an organisational perspective, and second, because of academic interest: how do families in extreme situations cope with the challenges, their strategies and resilience. The eventual understanding is that the "caregiver identity" influences migrants to Beijing for their children in their decisionmaking. This further results in emotional and mental stress yet have become a role they use to cope with their current problems.

\section{LITERATURE REVIEW}

As seen above, though statistically speaking, the group examined is significant to an extent, the matching policy seems to be limited and indirect towards their identity. Moreover, when researching, it appears that there is a lack of research and theories specifically for this group. However, from observation, many parents seem to fit a "caregiver role", which, according to Eifert et al. (2015), could be defined as "anybody who provides unpaid help to an unwell person." As these caregivers often are family members, they are usually referred to as family caregivers. A certain degree of studies from a nonChinese context have addressed this concept, which may help grasp on to the group's identity; hence, answer the research question.

\subsection{Engulfment of Identity}

Caregivers are a social role but also an identity. Identity, as defined by Burke (2006), is "the selfmeanings that define who one is." In the case of caregivers, the role of a caregiver "engulfs" the identity of that caregiver when the caregiver spends most of his/her time on care rather than individualistic aspects, which results in his/her previous identity "fading away", as stated in Heward et al. (2011), which studies the caregivers of "individuals with multiple sclerosis" and reported that many of the caregivers, no matter previously identifying as "homemaker, part of a parenting team or breadwinners", are now struggling with "running the home independently", which then suggests that the burden of the role "engulfs" oneself. [6] A variety of reasons may cause this change of identity not only limited to the intensification of the role but also the realisation of through observation of the care receiver and the re-examination of the relation between the caregiver and the recipient, as demonstrated in the study Sherrell et al. (2001). When examining a female adult child caring for her parents, Sherrell et al. (2001) observed that she no longer sees her "parents as protectors, but rather as needing protection, they (she) must shift their (her) own identity..." [10] The change in identity is also seen to be challenging for the caregiver, as according to Burton (2006), this "additional responsibility and loss of personal abilities..." would result in caregivers focusing on "what they had given up being a carer." These studies examine the identity changes of carers for the elderly, which, though being quite different to this study as the caregivers in this study are for children, seem to be applicable. The caregivers examined may feel a sense of impotence after the caregiving role eventually engulfs their character. [3] However, in this study, as they migrated to Beijing, they are faced with a new environment that may also contribute to a shift in identity. Therefore, it must be kept in mind that though such phenomenon of an identity shift may be seen, it cannot be simply contributed to the caregiver role engulfment.

\subsection{Family Obligation}

Furthermore, it is also important to point out that the caregiver role is often considered a family obligation, a 
social norm. For instance, it is more common for females to be caregivers than their male counterparts due to societal expectations. When examining individuals living with memory-impaired spouses, O’Connor (1999) found that these individuals are expected to be obligated as caregivers for their spouses, else immoral. More importantly, for many, this was unquestioned, as the belief is so strong. [9] The claim is supported in a study by Navaie-Waliser et al (2002)., a study that studies the characteristics of the primary caregiver by showing that most of the complex tasks such as dressing changes were completed by Women and that over 85 per cent of the sample surveyed are in a family with the care recipient. [8] From my personal observation, this would seem to be the case in many of the families who came to Beijing for better medical care. Often that only mothers or grandmothers take care of the ill children, while their fathers do part-time day jobs. This phenomenon could be interpreted through the explanation that caregiving seems to be a gendered family obligation, helping to form a sound hypothesis.

\subsection{Alteration of relation}

As there is a previous relationship in family caregiving and the relationship has been altered due to the caregiving relation, the caregiver may previously have a shared identity with the care recipient but is often changed, as seen in Hasselkus and Murray (2007), where the study finds many participants trying to reconnect with their parents with dementia as they feel a loss of relation, which is often done by appreciating small instances with the care recipient. In a scenario mentioned by a caregiver who cares for her mother where she takes her mother out for lunch, the caregiver explicitly referenced instances where her mother thanked her for lunch, which was a rare but memorable instance for the caregivers, as the author states, "the meaning of such incidents seemed especially potent." [5] This particular study examines caregivers for elders with dementia which is drastically different from the study object in this study. Dementia would, as commented in the study, disrupt the previous relation the caregiver had with the care recipient, while the care recipient in this study remains strongly attached to the caregiver as the care recipient are children. Nevertheless, the study is an example of how the caregiving role contributes to an alteration of the relation between the recipient and the carer and could be an important theme in this study as well.

The former studies in the literature review can act as an example as to the methodology of this study, but, more importantly, to assist in the analysis, where the logic employed can be similarly used here. The definitions of specific concepts, such as "caregiver" and "identity", could also be used as a reference to better understand the terms in this study. The findings of these studies can allow for a wider scope, making it possible for the limited data produced in this study to be taken in a larger context globally, ultimately allowing a better contribution towards the concepts mentioned above. More specifically, the studies allow the researcher to understand the main arguments regarding carers and the policies already raised.

In this study, instead of focusing on the care for the elderly, which is what most studies mentioned studied, it would focus on the caring for children with diseases, an area not so often explored in caregiving identity.

\section{METHODOLOGY}

The research data would consist of recorded face-toface personal interviews using the Chinese language with parents in the Children Hope Foundation project and their observed day-to-day actions. These interviews were previously noted to the foundations, and interviews were done in private, and the topic of this study is introduced to the respondents. All interviews were recorded by phone and transcribed later.

The method is decided with similar reasoning as Hasselkus and Murray (2007). They made two assumptions, which could and should be applied in this study: "(a) narratives are a saliant source for understanding the nature of an experience, and (b) meanings associated with the dementia caregiving experience (in this study, ill-child caregiving experience) are interpretable through narratives about people's biographical contexts, their routines of everyday life, and their social interactions." [5]

Of the total 6 interviewed subjects, 3 were mothers, and 3 were fathers. Their children's illnesses mostly range from brain tumours to leukemia, with two respondents who did not identify their children's illnesses. All came to Beijing after 2018, and the most recent came in august 2020 . The interview lengths lasted between 15 minutes to 1 hour, asking them about their general experiences in Beijing caring for their child and their experiences at their hometown, along with questions about their current needs and support that would better their lives. Moreover, the experiences I had and observations made during my time working with these families would be useful data for analysis.

As the research method focuses on collecting narratives, the interview may be rather unfocused, and the interviewed subject may stray off-topic, hence, resulting in difficulties in finding information that's relevant to the research question. Furthermore, the method is rather time-consuming, which may mean fewer respondents are interviewed. Nevertheless, this interview method could be advantageous because of the flexibility of the method and how narratives mark important moments of the caregiver and would outline the most significant features of the relation between the studied group and their children. 


\section{DATA AND ANALYSIS}

The six respondents interviewed were scattered across the foundation's nursing homes in Beijing. Out of the six, two respondents came from a nursing home in Dongcheng District, three respondents came from a nursing home in Haidian District, and the last respondent came from a nursing home in Chaoyang district. There are ten nursing homes that are operated by the Children's Hope Foundation currently in Beijing.

The first two respondents I interviewed came from a foundation-provided nursing home in the city. I, the interviewer, is acquainting with this facility, having to come to this nursing home since November of 2020 for multiple visits. Therefore, one of the respondents, XS's mother, was relatively familiar with me and expected my interview. She had an obvious accent, and I, according to experience, would say that she rarely leaves the house apart from shopping. The other respondent, however, I have never met. His wife and child, YT, were both not at home, and he was packing alone, as the family was bound to return home soon, which, according to him, is a result of their child's situation stabilising. During the interview, YT's father was visibly unrelaxed and seemed slightly uncomfortable at my presence. On the other hand, XS's mother was quite relaxed and not focused on the conversation.

The other nursing home in Haidian District housed three families, and the three respondents interviewed represents all three families. The facility includes three sick children: QQ, QW and XY, all with brain tumours of different sorts. QQ's mother (who was interviewed) spent the most time in this nursing home out of the three respondents. Another respondent, QW's father, was a businessman, was said to be on the rise of his career when his son fell ill. XY's family is drastically different from the previous two economically. During and after the interview, XY's father repeatedly emphasised that he was a poor farmer and that it was "a miracle that he got married" when taken into consideration how simple and crude his property was. These three respondents were eager to be interviewed and not shy from questions.

The last respondent came from a nursing home in the Chaoyang district. She is the mother of JY. From recollection and notes, she was relatively cooperative during the interview but broke down to tears during the interview, especially when recalling the moments when her child was on the brink of death.

Through conversation before the interview, they assured me that they are informal caregivers by definition as they provide "unpaid help" for an "unwell person." [4] This allowed the interview to progress.

\subsection{Migration}

From the interviews, I found that as these families' children got ill, it caused several other external changes, first, the change in location and occupation. Though identity is defined as "the self-meanings that define who one is" [2] for this study, a different geographical surrounding and other changing factors mentioned above may provoke a new reflection of one's identity. During the interview, she informed me of the family's previous situation: (The letter "I" stands for the interviewer and " $R$ " stands for respondent, all interviews are translated from Chinese original)

R: JY's grandfather worked in Beijing, his father worked in Xi'an, and he and his grandmother were also in Xi'an

Later in the interview, she also mentioned how the family came from Henan province, which demonstrates the family's previous complexity. Everything changed after her child got ill, however, as she told me during the interview that she has not worked ever since 2016 because she needed to take care of her child and currently, she lives in Beijing with her child.

Similar migration patterns can be found in other families as well, where a previously disunited family was united because of the child.

Through migration, we also get a hint at the concept of family and how it plays in with the caregiver role. Often found amongst the interviewees, of which none were from urban cities, was that the grandparents took care of the children and the children's parents worked in urban areas nearby, basically how JY's family operated. However, as they migrate to Beijing, the caregiving responsibility shifts to the parents, which seem to display a "caregiving hierarchy" in the family, where when the responsibility of this role got heavier, the role gets passed down from the grandparents, who often lived in the family's place of origin, to the parents, who are often previously migrant workers. It is the locational status that seems to define who the current child lives with.

Connecting back to their migration pattern, in XS's mother's discussion about the allocation of responsibilities between the family, she mentioned how XS's father was in charge of transportation. In a way, this relates to migration, as it is with migration that forced them into an unfamiliar environment. This further influenced their decision making and allocation of responsibility. However, in XS's family, this eventually resulted in his mother taking on more of the caregiver role while his father had the opportunity to find part-time employment. Logically, the change in external job status would influence not just how others view them (changing 
their social status) but also how they view themselves, their identity. Interestingly, in the example above, it is the knowledge that caused this role allocation, and XS's mother, who lacked knowledge about the city (possibly due to her farmer background), partially resulted in her taking on the caregiving role. Hence, in this case, migration could be said to be a factor for why some parents take on the caregiver role.

Overall, migration plays an important part in dictating the roles of these parents and influences their identity, but it also may mean challenges for them as well. As seen in XS's mother's situation, XS's mother was unfamiliar with the surroundings and spent a long time familiarising the environment. Before that point, she was confined. Further problems were mentions by JY's mother, indicated her initial panic when she came to Beijing with no knowledge of which hospital to go to. These challenges, I believe, may very well affect many others.

\subsection{Gender}

Adding to the section above, gender can also be considered a relevant theme, though maybe not as major as the previous. This remains important as the data found seems to challenge the previous discussions involving gender in caregiving.

In the literature mentioned above, many documented how the caregiving role is often gender orientated. For instance, Navaie-Waliser et al. (2002) stated, "most unpaid caregivers are women" and statistically concluded how most complex tasks in caregiving are more likely to be handed to female caregivers to complete. Nevertheless, during the interviews, I did not encounter the situation mentioned in that study and others which argues that most of the primary caregivers were women. Instead, there is a fair share of male and female parents caring for their children in most of the nursing homes I visited. From the interviews, I have learnt that such allocation is mostly intentional. For instance, in XS's family, where XS's mother was to stay at home and XS's father to work and transport XS to the hospital, XS's mother explained that this was because of her lack of education and inability to navigate around Beijing, while XS's father was familiar with the new environment. On the other hand, families such as XY's had both parents care for the child and transporting the child to the hospital, sharing the responsibility rather than splitting the task. Hence, though some female parents are seen to take on the caregiver role in these nursing homes because of gender norms, many do not, which is explained by the interviewees that this caregiving process is more about parenting rather than gender.

Though gender has been, in previous studies, considered linked with the "caregiver's identity." However, this paragraph above argues that gender is not a seeming direct factor that shapes the caregiver or the role itself; their identity is not especially affected by their gender.

\subsection{A Tough Life}

Another external change is the change of personal freedom. As these parents leave their hometown for Beijing, they usually are forced to abandon their previous job, leaving them unemployed. This provides them with ample time to care for their children, who, unlike the studies reviewed in the literature review, has some form of serious chronic diseases, many of which are very threatening, which, left-unattended, would be possibly fatal for the child. In other words, their unemployed life allows them to be a full-time caregiver. As YT's father puts it:

I: Where does the money for seeing the doctor in Beijing come from? Is it from you working here?

R: Umm, I do not work here in Beijing while taking care of my child as we often go to the hospital, and I do not have time to work.

Furthermore, if I recall correctly, after interviewing JY's mother, I was ready to leave and, therefore, asked her where the closest subway station was. She responded that she did not know, a surprising answer, considering that she came to Beijing in December of 2019 and have been here for quite a while.

These moments may indicate just how restricted their personal freedom may be due to their children's dangerous circumstances, a phenomenon which is reported in Burton (2006) as well. Burton (2006) also quotes the emotional distress of a caregiver from the dependency of her care recipient: "But now, as it's built up, he's blind as well and has a catheter, and I have to do everything for him ... I mean emotionally it's exhausting (Wife of an older person with physical and sensory disabilities)" From such quotes, we see that Burton (2006) found that the dependency of the care recipient which limits one's freedom takes an emotional and physical toll on the caregiver.

A similar logic can be applied in this study, even though it is unlike in Burton (2006), as no specific questions were asked about how these families' circumstances changed over time. During the interview, when these families introduced their situation, they often mentioned the frustration and mental strain at first when their children were first diagnosed, and they often were forced to travel across China to find a suitable hospital. In other words, the situation was mentally and physically exhausting for them. Even though at the time of the interview, the families no longer needed to constantly travel across cities, as most of the interviewed families' children's illnesses are stabilising or even recovering. Nevertheless, a logical assumption can be made that the pressure of the child's situation, which already limited 
the parent's freedom, would have a damaging emotional and mental impact.

In conclusion, the unemployed life these parents have is not a carefree life. Instead, it is a mentally straining life, which maybe because of the caregiver role adopted by them as they were able to allocate their time fully towards their child.

\subsection{Coping and Resilience}

The concept of a "caregiving identity" can not only help comprehend their identity but also contribute to understanding how they can cope with the existing problems.

Throughout the interview, I was surprised at the amount of medical knowledge these parents withheld, considering that XS's mother was a farmer in the countryside and that YT's father was a migrant worker, both of whom had occupations that did not relate to the medical field. For instance, when asked about XS's situation, his mother said the following:

$\mathrm{R}$ : (Complete) recovery is difficult as the medicine used has not yet been fully absorbed by his body; more drug use would only result in resistance to it, which is why we now use enhanced medicine......later, we would use anti-infectives.

When I interviewed QW's father, whose son was recovering from a brain tumour surgery, asking him to introduce his child's situation, he also displayed an understanding of some medical concepts, as shown below:

R: At first, when going to (Beijing Tiantan Hospital), the kid's brain tumour was relatively large, five centimetres in length. This resulted in severe hydrocephalus and intracranial hypertension, making it a dangerous situation.

Though, in this case, QW was known in his nursing home as a well-taught businessman, he never specialised in medicine or biology. Hence, in both cases, the respondents could be assumed to have not participated in any biomedical study, yet they understand certain medical concepts, more specifically, concepts closely related to their respective children's diseases.

As they uttered these terms with, I recall, confidence, it could mean a few things. For one, mastering these terms, which, considering their background, would require much effort, could attempt to understand their children's situation, demonstrating their attention towards their child. The reason why this attention is important is that it demonstrates a willingness to sacrifice from the caregiving parents: not only do they care for the child physically, but also, they are willing to spend time to understand the children's condition. This is, in fact, somewhat surprising, considering that in previous studies, such as in Burton (2006), many caregivers tend to despise the role, especially if the role adds pressure towards them. However, here, these parents as caregivers are rather willing to learn more about the care recipient's situation and places their priority in this role. This may demonstrate how this newly found role has become something that these jobless parents embraced as a new "job," a replacement-a shift in identity.

Furthermore, when asked about their most positive experience here in Beijing was, a question inspired by a similar one in the study Hasselkus and Murray (2007), XS's mother directly expressed her distress as shown below:

I: What do you think is your most positive experience here in Beijing?

R: Most positive experience? I have not yet had any positive experience; everything seems bad. Because of XS's situation, though I thought we could go home, the plan failed after his situation relapsed.

On the other hand, YT's father shared a different view:

I: What was a positive experience here (Beijing)?

$\mathrm{R}$ : Experience, hmm, my child is quite positive about going to the doctor.

I: So, the child recovering?

R: Um, no, it is how he (the child) wants to be better. He has more faith in himself which inspires us, parents, too.

Through these examples, the respondents discussed their answers to this question regarding their children's current illness, a pattern seen when asking other respondents the same question. From an interviewer's perspective, the question here, "a positive experience," asks the respondents to mainly discuss their situation and how they feel, possibly about the medical facilities and Beijing's general environment. However, the responses seem to differ from what the interviewer hoped to extract from this question, focusing on their children's situation. Though the interviewer did alert the respondents about how the interview would concern caregiving and their children before the interview, I would argue that such linking between the child's situation with the parent's emotion and wellbeing is entirely spontaneous, and, when considering how their mastering of medical knowledge, I believe it shows how currently, this group's priorities and focus is solely on their child. This argument can be further strengthened by a story told by JY's mother:

R: Well, if we (the respondent's family) can make it and my child can get better, we are grateful. Any glimmer of hope of recovering is worth it.

I: True, the child is important here. 
$\mathrm{R}$ : She (her daughter) is very resilient and brave. She wouldn't eat anything she is not allowed (due to medical issues). Just to refer to a story, another mother in the compound bought some muffins and gave me one, which I placed on the table. My child saw and wanted it, which is why she later did steal it and snuck it into our room. She asked what it was. I responded that it was a muffin given to someone else. "Then could I eat it?" I said no and grew suspicious: though she was asking me for permission, she was trying to be tricky. I then said, "where is the cake." "I didn't touch it." I went and saw that she already opened the box, but it was untouched. I immediately told my child, "You have to know, some food we can eat, others we simply cannot eat."

This detailed retelling of an event illustrates the "resilience" of the respondent's child, which, after the interview, she does mention multiple times. We see again how the respondent discusses her experience in accordance with her child's, yet this time the respondent uses the phrase "worth it." From the many interviews, the respondents have mentioned the major sacrifices: the medical expenses, the time spent, but it seems that the final criteria for whether this whole "operation" of going to seek medical support lies on the situation of the child. For example, in JY's case, the child is recovering and obedient; hence the effort spent is worth it. This is similar in YT's case, where his child is willing to get better, which allows him to state that it is a positive experience. $\mathrm{XS}$, however, is not doing so well, which directly impacted XS's mother's mood. However, at the time of the interview, YT's family was in heavy debt, as YT's father discussed how most of the money used is "borrowed money." Nevertheless, they still declare their actions as "worth it" which, not just shows their priority but also gives a success criterion to this new role that they have taken on.

When combining this criterion with their manifested medical knowledge, a picture is put together of their new role mentioned before. It is a caregiver role, which the above analysis suggests is purely centred around the child or the care recipient. As their top priority is their child, they are willing to take on this freedom-limiting role for their child, to protect the child and to attempt to understand more about their child's situation. This creates a different relation between the two, effectively making the child a patient-like character while the parent becomes his/her guardian.

The reason why these parents take on this role, I believe, is due to a change in value. In the interview with XS's mother, she addresses how when her child was not diagnosed, her son was in boarding school and that they never spent too long together. Many other families' parents often worked in other places, leaving their children with the child's grandparents. However, just as how XS's mother said in the interview that she hoped to provide her child with "a nutritious meal", these parents still cared for their children, yet there was no extreme pressure as these children were perceived to have a long life. But as a life-threatening disease emerged, these parents suddenly felt pressured to provide all the care they could possibly provide, considering that the disease may be fatal. In other words, in this process of caregiving, a strong family bond is developing under this perceived change in their child's life. From the data, we see how these parents use this bond to justify their actions as a criterion, which, I perceive, allows them to better cope with the economic pressure, limited personal freedom mentioned above.

This method of coping relies on the emotional care these parents have towards their children, who are in constant threat. However, hypothetically, it can be imagined that without such distraction, the sheer presence of the mounting loans could be devastating to these families. Though I have never witnessed such a situation, there are often stories in the foundation about those families which have lost their child to the disease. The usual ending is that they return to their hometown, working day and night to pay off their debts. Though in hindsight, the role does support these families as they at least have some form of hope in their life due to their focus on the child amidst the harsh circumstance.

This aspect of caregiving shown in this study does not challenge most of the expected "caregiver identity" attributes mentioned in previous studies. There are alterations of relations, engulfment of previous selfidentity etc. However, as shown in the first section, the researcher did not find much about a gendered caregiving practice. Instead of females assigned more complex work, male caregivers are also seen to be taking on rather complex roles such as housework and preparing meals. This may challenge the previous idea that there is a strong gender pattern in caregiving in circumstances where there is immense pressure, ones mentioned in this study. Nevertheless, the lack of a large sample and specified data does not allow me to strongly argue such and leaving the possibility that such phenomenon is coincidental.

Though this answer may be satisfactory for now, questions remain about their coping strategies, especially regarding the formation and conclusion of the strategy. One cannot easily form such a heavily dependent identity in a short time, nor can the new caregiver identity, presumably, easily change to another relationship after the child has recovered and the parent returns to work. These questions remain important no matter from an organisational point-of-view or even a policy point-ofview, as having knowledge about these groups of people' psychological identity would allow more targeted support towards these people, helping them cope with the burdens of loans after leaving Beijing. 


\section{RECOMMENDATIONS}

Due to the mental and emotional impacts mentioned in the analysis, strategies can be developed to better support these parents. The root of this problem lies in the freedom-limiting role of a caregiver. Some may suggest that paid caregivers can substitute parts of these informal/family caregiver's work, allowing more freedom which, theoretically, lessen the mental strain from constantly needing to care for a child in possible life-threatening conditions. I understand that such paid caregivers already exist, and from personal experience, I know that some hospitals provide such service. However, the problem remains with the money needed for hiring these people, as the medical bills often exhaust these parents' banks.

Also, one can consider that the emotional and mental impact does not just originate from a tiring caregiver role but also from the pressing medical bills. For many of these families, the money used to pay the medical bills come from loans and borrowed money. The sheer presence of the need to repay such an expense would add pressure to these parents. In such case, medical bills could possibly be lowered towards certain groups of people, for instance, in this case, those who require medical aid for serious chronic diseases (known to be "money-drainers") and are estimated to be unable to pay the payment for the full course of treatment.

Furthermore, NGO's can benefit them through raising awareness and provide possible services which can allow an easier process for hospitalisation, which is identified as a challenge in the section analysing migration. As caregivers who really care about their children's situation, many respondents expressed their previous frustrations when first arriving in Beijing and not being able to find the best hospital for their children's situation. After the interview, JY's mother talked about how she guided another mother, whose child was in a similar circumstance with hers, through hospitalisation and evidently reduced her stress. Hence, guides may help reduce the emotional stress produced.

\section{CONCLUSION}

Though this study may not be as thorough, it could indicate certain changes in identity for those who migrate to Beijing to take care of their sick children, which includes a general shift towards being a "lifeguard" for their children who operates on the fear of loss of their child and as an accountant in some ways to sustain hope for possible financial recovery, a coping strategy. The migration process also takes a toll on their situation, making some take on a "freedom-limiting" caregiver role which is said to cause emotional stress, while allowing others to take on part-time work. Connecting back to the hypothesis, the findings did address a change in identity and a conformation towards a caregiving role in order to seek to cope with the harsh circumstance. However, there is no strong sign indicating a complete shift from their old identity. Instead, they do still possess the former parental identity as discussed in the migration section while also demonstrating a forming of a new identity (e.g. through learning medical knowledge).

Throughout this study, the concept of "caregiver identity" on multiple occasions, mostly to help make assumptions about their qualities and help understand the problems they are currently facing. The above-mentioned conclusions I made coincides with certain findings in other studies yet differs in some ways. This includes how, from observations, there is not a strong gender norming situation occurring in these "nursing homes", which somewhat differs from previous literature on caregiving. Furthermore, a basic analysis of the relationship between migration and the selection of caregivers is made, a field which I did not find much information about. Both of these factors may enrich the attributes and formation of a "caregiver's identity."

Furthermore, there is the question of how to better support them. In the analysis of these parent's unemployed life, we understand the emotional stress they are enduring. After the analysis, there was an emphasis on the proposed two main kinds of support these parents need: money and guidance. In the analysis of these parent's coping strategies, we get a glimpse of how they focus their attention on their child as a way to cope with the stress, where there was an admittance that it may be beneficial if NGOs can tend to their psychological needs not just during their stay in Beijing, but also after they return, to help them deal with the stress from the economic worries that may pursue. Moreover, during the interviews, the respondents responded about how charity organisations can better support them. Some emphasised the necessity for easier channels for donations, while others suggested a possible cut in medical fees for people, like them, who are having difficulties in paying the medical fee.

\section{ACKNOWLEDGMENTS}

Special thanks to the Children's Hope Foundation for support during the study.

\section{REFERENCES}

[1] .Cdc.gov. n.d. About Chronic Diseases | CDC. [online] Available at: <https://www.cdc.gov/chronicdisease/about/index. htm> [Accessed 17 September 2021]

[2] Burke, P., 2006. Identity Change. Social Psychology Quarterly, [online] 69(4), pp.81-96. Available at: <http://www.jstor.org/stable/20141729> [Accessed 17 September 2021]. 
[3] Burton, M., 2006. Grounding Constructions of Carers: Exploring the Experiences of Carers through a Grounded Approach. British Journal of Social Work, 38(3), pp.493-506.

[4] Eifert, E., Adams, R., Dudley, W. and Perko, M., 2015. Family Caregiver Identity: A Literature Review. American Journal of Health Education, 46(6), pp.357-367.

[5] Hasselkus, B. and Murray, B., 2007. Everyday Occupation, Well-Being, and Identity: The Experience of Caregivers in Families With Dementia. American Journal of Occupational Therapy, 61(1), pp.9-20.

[6] Heward, K., Gough, B. and Molineux, M., 2011. Change of identity: the psychological and emotional impact of caring for someone with multiple sclerosis. Social Care and Neurodisability, 2(1), pp.21-32.

[7] Lu, F., 2020. Dynamic Analysis and Prediction Study on the Changes of the Discharge of Patients Coming to Beijing from Hebei Province. Chinese Journal of Health Policy, [online] 13(1). Available at:

$<$ http://journal.healthpolicy.cn/ch/reader/view_abst ract.aspx?file_no=20200109> [Accessed 17 September 2021].

[8] Navaie-Waliser, M., Spriggs, A. and Feldman, P., 2002. Informal Caregiving. Medical Care, 40(12), pp.1249-1259.

[9] O'Connor, D., 1999. Living with a MemoryImpaired Spouse: (Re)cognizing the Experience. Canadian Journal on Aging / La Revue canadienne du vieillissement, 18(2), pp.211-235.

[10] Sherrell, K., Buckwalter, K. and Morhardt, D., 2001. Negotiating Family Relationships: Dementia Care as a Midlife Developmental Task. Families in Society: The Journal of Contemporary Social Services, 82(4), pp.383-392.

[11] Childrenshope.org.cn. 2021. About us - children's hope relief foundation. [online] Available at: <http://www.childrenshope.org.cn/pages.php> [Accessed 17 September 2021].

[12] 2021. Public service information release of basic medical insurance for direct settlement of medical treatment in different places across provinces (Phase Thirty Two)-The five regions in Southwest China took the lead in launching a pilot program for direct settlement of outpatient and chronic disease expenses for hypertension and diabetes.. [online] Available <http://www.nhsa.gov.cn/art/2021/2/26/art_18_451 8.html> [Accessed 17 September 2021].

[13] Gov.cn. 2017. Interpretation of the policy of direct settlement of medical treatment across provinces and other places. [online] Available at: <http://www.gov.cn/fuwu/2017-

09/27/content_5227799.htm> [Accessed

17 